\title{
ANY LESSON FROM THE HISTORY OF SUSTAINABLE DEVELOPMENT?
}

\author{
Miloslav LAPKA ${ }^{1}$, EVA CUDLÍNOVÁ $^{2}$
}

${ }^{1}$ Faculty of Philosophy and Art, Charles University Prague, Celetná 20, Praha 1, 11000 , Tel.: +420387775615. Fax.: +420385310249. Email: milala@usbe.cas.cz. (main author)

${ }^{2}$ Faculty of Economy, South Bohemia University, Ceske Budejovice, Czech Republic.

Studentská 5, České Budějovice, 370 05, Czech Republic. Tel.: +4207772506. Fax.: +420385310249. Email: evacu@centrum.cz.

Received: $1^{\text {st }}$ September 2009, Accepted: $23^{\text {rd }}$ February 2010

\begin{abstract}
Have we still got time for sustainability and reasonable application of ideas of sustainable development? It has been just over twenty years since the Brundtland Commission Report but, taken as an axiological term; sustainable development resonates with older historical horizons. At the heart of a long running history we are beginning to articulate more or less sustaining relationships between man and nature. We have described the (human) needs in the environmental, economic and social dimension of sustainable development to show some amazing shift in perception of sustainable development from local to global level. We are convinced that historical lesson of sustainable development shows there is no more time for sustainability, but time for SOStainability. Our proposed S-O-S in SOStainability means Save Our Sustainability! SOStainability represents the need to end the compromise between economic development and natural life supporting systems.
\end{abstract}

\section{INTRODUCTION}

The definition of sustainable development (SD) provided below was first published in 1987, in the report of the Brundtland Commission. This implies over twenty years of "history". Twenty years in history means nothing compared to the duration of ancient civilization, so why should we talk here about history at all? SD nowadays is connected with many environmental hopes; since the year 2000 SD has become so frequently used in many scientific fields that it seems to be one of the leading contemporary ideas. Would it be possible to find about 21, 500, 000 links on Web pages (Google) dealing with SD? Would it be possible to find about 17000 scientific results of SD in ISI Web of Knowledge without some historical roots and axiological resonation behind this idea? The founding definition of SD: "Humanity has the ability to make development sustainable - to ensure that it meets the needs of the present without compromising the ability of future generations to meet their own needs" does not give us scientific tools or tell us how to sustain something, or how to develop something. This definition also gives us no time limits when to sustain and when to develop. Furthermore, there is even no explicit definition on the needs, dealing with ethics, human rights, human values, intrinsic values of ecosystems, etc. On the other hand, this pre - scientific term empowers human imagination and the 
sharing of some subjective and collective experiences. The term SD resonates with these shared experiences.

There is rich discussion on the conceptualization of SD. Two main streams can be found: critical skepticism represented for example by Wilfred Beckerman (1994), stressing SD is not useful concept because of logical and scientific confusion, as well as defending positions of Herman Daly, Michael Jacobs, and Henryk Skolimowski (1995) and other authors (Redclift, 1993) who are also critical, but consider SD as a new level in human thinking about the relationships between man and nature.

Looking at SD from the "meet the needs" point of view, SD can be considered to be a result of the disillusion. In the 19th century the shift from the agrarian-based to the industrial-dominated society in developed countries brought the application of industrial processes to all structures of social life, Sociologists like Comte, Spencer, Weber, Durkheim, and Marx were fascinated with this process, and sociology found its primary subject of research in the great industrial changes in society. Parsons (1966) labeled this period as the "society of plenty." But, of course, there were constraints and limits, and the first wave of "industrial revolution" transitioned into the second wave of the "postindustrial society" (Bell 1973) and, perhaps now, the third wave of the "knowledge society" (Toffler, 1990) is upon us. These changes have been accompanied by the devaluation and delegitimizing of the idea that was once widely adhered to, namely, that the industrialization and modernization projects inherently yielded both development and humanitarianism. Now new criteria are emerging, including those of lifestyle, sustainability and delocalization (Sen, 1984). The peak of disillusion of some cultural and moral expectation on the one hand and business reality on the other, reached at some point around the 1980s. The publication of the Brundtland Commission Report highlighted the fact that current patterns of resource consumption and environmental degradation could not continue as they were and that in order to reduce the problem we are facing, the society must act as a whole.

SD represents mixture of scientific knowledge system, environmental values, ideology, social actions, moral attitudes, qualitative patterns as well as quantitative indicators and many other, often ambivalent, social constructions of the relationships between man and nature. „There was ready agreement in the literature that sustainable development implies linking what is to be sustained with what is to be developed, but here, too, the emphasis has often differed from extremes of "sustain only" to "develop mostly" to various forms of "and/or." Similarly, the time period of concern, ambiguously described in the standard definition as "now and in the future," has differed widely. It has been defined from as little as a generation - when almost everything is sustainable - to forever-when surely nothing is sustainable.“ (Kates, Parris and Leiserowitz, 2005).

Drawing on the discussion outlined above, we witness the attempt to break down the European dualism of man and the environment, culture and nature, economy and ecology, etc. Is there any chance to change it? Have we got time to change it? History of SD shows three opportunities for real existence of SD: environmental, economical and social. Are they integrated together? For the following essay we try to describe some selected samples of "needs" to follow the Brundtland's definition. We consider these needs to be behind SD pillars as driving forces shifting human perception and understanding of what SD means as well as its implementation. Is there some historical lesson to be learnt from these needs? 
We try to bring some answer in terms of when to sustain. The implementation of SD is a great topic of many studies; one of the most representative ones can be found in the report called Our Common Journey, (1999). (Board on Sustainable Development, National Research Council, 1999) There are many indicators as well as scientific concepts and arguments in terms of what to sustain, how to sustain, what to develop, but the question when is often reduce on the vague statements like now and in the future, forever, in the next 25 years. We consider this question important for the perspectives of SD itself. This is the reason of our proposed term SOStainability in the conclusion of this essay.

\section{USING METHODOLOGICAL CONCEPTS}

The concept of SD is a complex covering at least three widely used pillars: environmental, economic and social. The Johannesburg Declaration explicitly speaks about "a collective responsibility to advance and strengthen the interdependent and mutually reinforcing pillars of sustainable development-economic development, social development and environmental protection - at local, national, regional and global levels. (The Johannesburg Declaration on Sustainable Development, 2002)

Broad agreement on these three pillars does not entail any precise definition of them. The environmental pillar is more or less understandable as the opposite to human activities and results; more complicated is the situation with regard to distinguishing between the economic and social pillars of development. Social development is often connected with human society, social values of non-economic nature, with development of human spirituality, etc., as opposed to economic or financial values.

Using the term SD in our article, we are close to academic version (Mebratu, 1998) based on the facts that a) nature is a highly self-organizing system b) effective protection of the environment means to incorporating environmental values needs into economic, as well as social and cultural values.

Our intention is to describe some evolution of "needs" in these three pillars. "Needs" in this context mean human needs advocate to sustain nature. We consider these needs to be the driving forces behind SD pillars shifting human perception and understanding as well as implementation of SD. There is a useful concept of Maslow's hierarchy of needs (1971), based of individual psychological grow from basic cognitive: to know, to understand, and explore; through aesthetic: symmetry, order, and beauty to self-actualization and selftranscendence. Julian Marshall and Michael Toffel (2005) simplified this hierarchy using it for application on the human needs for SD - they call it four levels of sustainability. They begin with 1 . Human survival, 2. Health and life expectancy, 3. Species extinctions and human rights, 4. Quality of life.

\section{EVOLUTION OF NEEDS}

The longest history of needs to protect nature (later in intention of SD to sustain) is connected with the environmental pillar of SD. (Gottlieb, 1996). The environmental pillar of SD in our essay is connected with the needs to protect nature from the beginning based on the aesthetics (the sublime) and ethics of nature itself, etc. 
The need for protection of trees: There are many instances of protection of woods and trees dating back to the BC period. A. Leńkowa (1978) described an example from China 1100 years BC, as well as a popular story of the "environmentalist" Persian king Xerxes (517-465) and the first historical fact of tree protection. Herodotus of Halikarnas (485-425) reported the real story about individual tree protection. King Xerxes, crossing the river Meander near the town of Kallatebus in Lydia (the western part of Turkey today) was so fascinated by a well-built platanus tree (probably Platanus hispanic) that he left a guard there and hung a gold disc featuring the king's symbol on the trunk of the tree. Another important person in the European protection of nature was Alexander von Humboldt (17961859) and his term "Naturdenmal" - natural monument.

The needs to protect landscape as a scenery - national park: At the beginning of 1870 there were several expeditions and their stories about the rocks, waterfalls, lakes, hot springs and wildlife animals and power of nature. This gave the idea to a number of people that these wonders might be preserved by retaining public ownership of the land through the creation of a "national" park. In 1865 Thomas Meagher, acting governor of the Montana Territory, made the proposal.

These needs caught enthusiasm rapidly and the park was created on March 1, 1872, by the signature of President Ulysses S. Grant. In the historical declaration of national park act setting we can find among other sentences: „Be it enacted by the Senate and House of Representatives of the United States of America in Congress assembled, that the tract of land in the Territories of Montana and Wyoming, lying near the head-waters of the Yellowstone river, and described as follows.... is hereby reserved and withdrawn from settlement, occupancy, or sale under the laws of the United States, and dedicated and set apart as a public park or pleasuring-ground for the benefit and enjoyment of the people; and all persons who shall locate or settle upon or occupy the same, or any part thereof, except as hereinafter provided, shall be considered trespassers and removed therefrom."

The need to protect landscape as a cultural system: In 1992 the World Heritage Committee adopted three categories of cultural landscapes to be integrated into their operational guidelines 1. Landscape designed and created intentionally by humans. 2 . Organically evolved landscape. 3. Associative cultural landscape. Evolution of the need to protect landscape as aesthetic scenery to the landscape as a supporting life system on the land system reaches its contemporary goal in the European Landscape Convention.

In the European Landscape Convention signed on March 1, 2004, (European Landscape Convention, 2000) all surrounding landscapes are adequate objects of social care and responsibility, from moral appeal point of view. „Acknowledging that the landscape is an important part of the quality of life for people everywhere: in urban areas and in the countryside, in degraded areas as well as in areas of high quality, in areas recognized as being of outstanding beauty as well as everyday areas". There are many discussions are on the brief definition of landscape. "Landscape" means an area, as perceived by people, whose character is the result of the action and interaction of natural and/or human factors". Human factors, cultural construction, as well as natural and ecological background are unified there.

Few selected needs could represent some evolution in perception of what to protect in nature. There is a shift from the needs to protect the attractiveness of individual trees and 
forests to attractive landscapes featuring, for example wilderness or harmony or sublimity and so on. The latest European Landscape Convention protects landscapes in a general way. The focus on the object of protection is shifting, too, from emphasis on holy places to esthetical and ethical categories, from the protection of species, their habitats, biodiversity and nature, to the protection of the human natural environment, to concede intrinsic value of ecosystems as such.

The need to protect nature and/in economic and societal development is connected to the economic pillar of SD in this essay. No doubt, the British industrial era gave birth to the modern political economy, with Adam Smith (1723-1790) often being seen as the father of the modern political economy. His "An Inquiry into the Nature and Causes of the Wealth of Nations" from 1776 influenced the industrial revolution in Europe and the USA. (Smith, 1776).

The total separation of economy from nature is dated relatively late in 1860 with the appearance of Alfred Marshall and his theory of marginality where value does not depend on nature but it is based just on the utility of goods. (Marshall, 1920). Environment and nature were tightly connected within the economic schools of former times. The "Physiocrats" provide one example: based on the ideas of Francois Quesnay (physician of the Ludvik XVth court), this school fully accepted the role of nature for society physiocracy means the governance of nature. Classical economists such as Adam Smith and David Ricardo based their theory on Newton's research methods in searching for the laws of nature. Economic value in classical economics was created by work and nature. "In agriculture, too, nature works along with man; and even though its labour costs no expense, its produce has its value, as well as that of the most expensive workmen. It is the work of nature what remains after deducting or compensating everything which can be regarded as the work of man. It is seldom less than a fourth and frequently more than a third of the whole produce". (Smith, 1776).

The need of reconciliation of economy and ecology. The need to unify nature and economy on an appropriate level and not ignoring the ecological paradigm can be found in ecological economics. Ecological economics is a new discipline which takes the environment into account, where the way of thinking is not limited to society and the optimal division of resources, but the planet as a whole. The limits of economic development within the whole biosphere are also taken into account. Among ecological economists we find two main branches. One branch (Pearce and Turner 1990, Drucker 1995, Pearce et al., 1998) is formed by the economists who believe in private property rights - their conviction is that sustainable development will come only from stable private property rights. The other branch supports communitarian forms of property rights and ethics (Schumacher 1989, Daly 1996, Daly and Cobb 1989). Criticisms of injustices connected with property rights were strongly expressed by the "anarchist" Pierre-Joseph Proudhon in 1840 in his book What is property? "If I were asked to answer the following question: What is slavery? and I should answer in one word, It is murder!, my meaning would be understood at once. No extended argument would be required . . . Why, then, to this other question: What is property? May I not likewise answer, It is robbery! without the certainty of being misunderstood; the second proposition being no other than a transformation of the first?" (Proudhon, 1840). 
Without any ambitions to go to the details of this complicated problem of property rights we can find needs for social justice, development of society and protection of the environment together.

The need for coordination in nature protection isare connected with the social pillar of $\mathrm{SD}$ in our essay, i.e. with civic society and political environmental values and movement.

The need to "wake up" public perception of nature protection: In 1949, Aldo Leopold (1887-1948) published A Sand County Almanac, a book of a great influence for the environmentalists in terms of new established land-ethics. (Knight and Riedel, 2002). Leopold wrote that evidence that no land ethic existed at the time was that a "...farmer who clears his woods off a 75 percent slope, turns his cows into the clearing, and dumps its rainfall, rocks, and soil into the community creek, is still (if otherwise decent) a respected member of society."

The environmental movement was further encouraged by Rachel Carson's book Silent Spring in 1962 (Carson, 1962) and its internationalization confirmed by the Friends of the Earth and the Greenpeace in 1971. The activities of the Club of Rome, which was established in 1968, exerted international influence. It gained popularity and became known throughout the world in 1972, following the publication of The Limits to Growth. (Meadows et al., 1972).

James Lovelock's books on Gaia - the first one called Gaia: a new look at life on Earth, (Oxford University Press, 1979) was not the only new look on evolution of the Earth, but also new arguments for "global needs" covering global responsibility. This line continues with Gaia: the practical science of planetary medicine, (Gaia Books, 1991) and the recent book The Revenge of Gaia. Why the Earth Is Fighting Back - and How We Can still Save Humanity (Allen Lane, 2006).

The need for coordination of nature protection on international level: The Earth Summit in Rio, Brazil in 1992 emphasized how the planet's environmental problems are linked to the economy and also to the issues of social justice. The era of global warming started, too: one of the conclusions was "...stabilization of greenhouse gas concentrations in the atmosphere at a level that would prevent dangerous anthropogenic interference with the climate system".

Following the line $($ Rio +10$)$ in 2002 - the Johannesburg Earth Summit revealed the social and environmental power of developing countries, through demands that their interests should be taken into greater consideration. The Kyoto Protocol was initially adopted in 1997 where 37 industrialized countries and the European community bound themselves for reducing the greenhouse gas emissions by an average of five per cent as against 1990 levels over the five year period to the year 2012 .

The Intergovernmental Panel on Climate Changes (IPCC) Third Assessment Report in 2001 found "new and stronger evidence" that humanity's emissions of greenhouse gases are the main cause of the warming seen in the second half of the 20th century.

The IPCC's Fourth Assessment Report in 2007 then concluded that it is more than 90\% likely that humanity's emissions of greenhouse gases are responsible for modern-day 
climate change. "Bali roadmap" was adopted in 2007 in Bali, the two-year aim to hammer out a new global treaty by the end of 2009 .

The Seal the Deal campaign before Copenhagen in 2009 started on behalf of the United Nations (UN). "The petition will serve as a reminder that our leaders must negotiate a fair, balanced and effective agreement in Copenhagen, and that they must seal a deal to power green growth, protect our planet and build a more sustainable, prosperous global economy from which all nations and people will benefit. There is no time to waste: stamp your vote and seal the deal!" we can find on the official website of the UN.

These particular cases show the case-based moral appeal. The need for cooperation in nature protection shows shift from the need to protect wisdom, beauty and ethics of nature, represented by local landscapes in the work of Aldo Leopold. We could continue with the need to protect endangering natural cycles contaminated by pesticides and ending with the awareness of global processes like Gaia and global climate changes. Then the needs came into action: summits on the UN and protocols. It is the first time that the need of global social justice, the rights and the need to prevent the damage on the nature for the future generations on the Earth have arisen. Of course, the description of particular cases is dealing more with political proclamations than with real SD changes, nevertheless, the needs should be considered as the initial indicators for the new perception of relationships between nature and man, man and nature.

In such situation it is no wonder that ecological and social needs are mentioned together as two equal parts which must be taken into account when dealing with the process of sustainable development. In spite of these "so clear facts" in research articles and political proclamations, the process of applying sustainable principles into real policy, must very often deal with the difficulty of deciding between the environmental and social goals. It is not an exceptional situation when these factors are more competitors than partners and one is finally preferred to the other. The tendency to prefer either the environmental or social needs depends to some extent on governmental attitudes towards the two kinds of definitions of sustainability that come from two starkly differing economic paradigms of sustainable development - weak and strong definitions of SD. (Özkaynak, Devine and Rigby, 2004).

Weak sustainability is based upon the work of neoclassical economists Robert Solow (1993) and John Hartwick (1990), and is an extension of the neoclassical welfare economics. This paradigm is based on the belief that what matters for future generations is only the total aggregate stock of man-made and natural capital and not natural capital as such. Natural capital is regarded as being essentially substitutable. (Figge, 2005)

Strong sustainability - does not allow such simple and clear definition as many different scholars have contributed their own views. But in essence among supporters of strong sustainability natural capital is regarded as non-substitutable both in the production of consumption goods or for providing utility. (Neuymayer, 1999). 


\section{DISCUSSION AND CONCLUSION}

With awareness of all the inaccuracies of generalization we can see the same shift in the evolution of the roots of SD: the pre-historic formation of the first dark unity of man and nature, often expressed by religions, to ecological consciousness of the universe of nature and man, man and nature. There are at least three kinds of reality in the acceptance and perception of SD idea:

- $\quad$ natural space with its own eco-geo- bio characteristics,

- the space of institutional and political systems

- $\quad$ the space of culture and ideas

Fig. 1: Dynamic model of the context of the evolution of SD
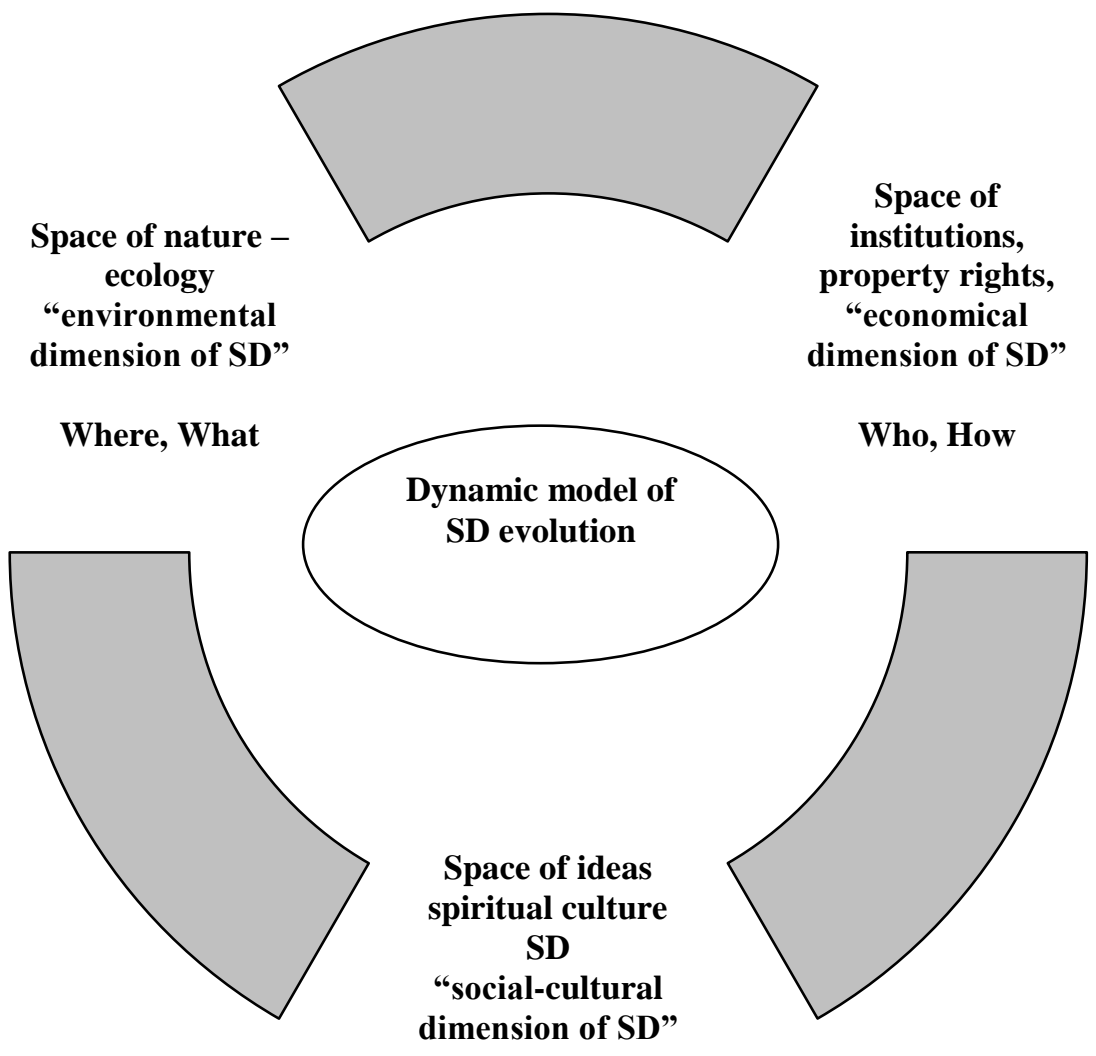

Why, When

Comments: This conceptualization produces a functional circle incorporating the spatial dimensions of nature (where - what), ideas (why - when), and institution (who- how). 
Looking for the dynamic model of SD it seems to be easy to reach the point of sustainability in near future and real time. Unfortunately it could be great illusion. The ways to the principles of SD in three realities mentioned in Fig 1 seem not to be synchronized. On the contrary, causality shows some negative feedback - destruction of the environment and negative consequences for the human social and personal life evokes the idea of some need for nature and landscape protection; disillusion and limits of the industrial development show the emerging values of nature; economy without any respect to environment shows how economic development depends on natural and human sources. Have we got a chance to synchronize these realities in one process? We are afraid not yet.

Table 1: Domination of functions

\begin{tabular}{|c||c|c|}
\hline Function & Manifests as & Period \\
\hline \hline ecological & natural facts & $\mathrm{BC} *$ to the 18th-19th century \\
\hline \hline institutional & $\begin{array}{c}\text { property rights and economic, } \\
\text { politic control of nature }\end{array}$ & $\begin{array}{c}\text { From the 18th-19th century up to } \\
\text { now }\end{array}$ \\
\hline \hline $\begin{array}{c}\text { spiritual - } \\
\text { cultural }\end{array}$ & ideas of SD & From 1970 up to now \\
\hline \hline
\end{tabular}

* Before Christ

Comments: Every "domination" mentioned in Table 1 has its own very long historical evolution. Evolution in this context means among other things that the previous functions are still valid and working well. This scheme gives us open questions related to the history of SD: the potentially dominant position of spiritual/cultural functions should indicate a turning point (in Europe at least) to respect for the ecological characteristics of space (landscape, biodiversity, protection of species, etc.) New ideas like SD, Amenity, Agro-tourism, Organic farming, Multifunctional agriculture and others are coming into their practical implementation. The real domination of "where", "what" and "who"," how" - the domination of intensification and global market is clearly visible in the everyday practical life. The proportion of these functions varies, taken individually, every historical period and every country has its own proportions. Generally speaking we are on the point of crossing historical limits to the understanding of the universe of nature and man. SD could represent one of the promising attempts.

Is there going to be any overlapping space-time-cultural system for realization of SD in higher than just local level? Have we got time for this realization on a global scale of biosphere? Intensive consumerism of west societies is no longer able to offer a long-term solution for the next generations and their identity.

The case of global needs: the question whether we have time for reconciliation the needs of economy and the environment on the global level is very complicated. There are numerous data indicating the growing power of political implementation of SD, for example according to the United Nations protocol, there is a small number of nations standing out of the process of ratification accepted in the world summits in Rio 1992 and Johannesburg 2002 (Agenda 21, etc). On the other hand, the real needs of global economy represented by great corporations mentioned below are still powerful driving forces with many consequences showing real power evoking the same question again: have we got time to realize our needs and the needs of future generations? Apart from the official proclamations of politicians about the equal weight of the three aforementioned roots of $\mathrm{SD}$, the real situation is subordinated to the division of the real power of international institutions mentioned above. These institutions have not only different strengths but also 
play different roles. Economic organization such as the IMF (International Monetary Fund), WTO (World Trade Organization) or World Bank play the role of "engines" in favor of progress and prosperity and the other ones such as the WWF (World Wildlife Fund), WHO (World Health Organization) fill the function of "brakes". Engines and brakes are both important parts of societal development, providing they are balanced. When the brakes are weak, they do not match the power of engines, it is a dangerous situation of driving acceleration without a real control to stop or change the direction. What is the power of these organizations? Apart from the official proclamations of politicians about the equal weight of the three aforementioned roots of $\mathrm{SD}$, the real situation is subordinated to the division of the real power of international institutions mentioned above. These institutions have not only different strengths but they also play different roles.

Governance of environmental affairs in its international dimension is arranged mainly through multilateral environmental agreements (MEAs) and international funds, enabling realization of the agreements. MEAs are agreements between states which may take the form of the so called "soft-law", setting out non-legally binding principles which parties will respect when considering actions which affect a particular environmental issue, or "hard-law" which specify legally-binding actions to be taken in working toward an environmental objective. The practical influence of these agreements and conventions mentioned above depends on national support in the form of a framework of national environmental laws. This part is fragile in terms of competition between environment- and economic growth- oriented international organizations. The US Marine Mammal Protection Act (1972) and Dolphin Law (1991) (Act of Congress, 1972; Urgese, 1998) illustrate how so-called trade agreements do indeed undermine vital domestic environmental and other public interest policies.

\section{When to sustain nature? Sustainability or "SOStainability"?}

Many projects dealing with sustainability have been undertaken. However, looking at the contemporary needs system in SD, we still cannot say that we have passed the turning-point toward sustainability. (Leiserowitz and Fernandez, 2008).

What seems to be very important to us, is the vagueness of the conception of time span in SD. Have we still got time to sustain and to develop? Are the life-supporting functions and positive feedback of the biosphere supporting human beings never-ending? Have we got the abilities and time to replace it by our own techno/systems in an emerging "anthropocene" era? (Not mentioning the rights to replace some evolution systems that have been developing for over 3 billions years)?

We do not believe we have got much more time, and in this context, it seems to be appropriate for us to adopt the term "SOStainability" to replace that one of sustainability.

There is no existing concept of "SOStainability", despite the fact that the Spanish language uses the word "sostener" for "keeping. In the final section we use "SOStainability" to convey an emphatic message for needs of future generations.

Why is it time to change the term sustainability to the term "SOStainabiliy"? Our proposed "SOS" in the term SOStainability means Save Our Sustainability! SOStainability represents the need to end the compromise between economic development and natural life supporting systems. It is an S.O.S. - there is no time for continuing the older and diluted concepts of sustainability. SOSstainability represents the failures of SD. It is a warning sign for our debates about the possibility of SD. SOStainability reflects the need for innovative 
local implementation of SD and the end to un-sustainable global consumer values. SOStainability is recognition of deteriorating natural supporting ecosystems for sustainability and the need to act quickly. SOStainability is required by a lack of social, cultural and moral values for sustainability. SOStainability is the deadline for taking SD seriously as a world developmental concept.

We could distinguish between SD as a concept and sustainability as a manifestation of a good ecological practice, the wisdom of ethnic culture, the values of rural culture, etc. In fact, the seeking of historical parallels of SD represents the seeking of cultural, social, environmental and historical parallels of sustainability of the environment, not the past exploitation of the concept of SD as it is defined above. The lesson from the history of SD shows that the time is over for sustainability. Good environmental, economic and social condition for real application is the past. Some conceptual as well as practical equilibrium among the needs to protect the environment, to unify economy and ecology and to reach the goal of international cooperation is still more methodological aim rather than reality. It means, there should be no time for where and what to sustain, despite of the excellent and humanistic ideas why and when to sustain nature. Looking at the system needs, the situation is also not so clear. Yes, there are good developed limits in SD indicators making some barriers for our growing anthropocentric and North-centric needs of wealthy countries. However, concept of these needs is like a pyramid, with the baseline of surviving of growing human population, not a system with feedback from quality of life to survival. There is a temptation to forget, in concept of SD, that biosphere itself is a highly organized system. It means it has its own feedbacks which we are a part of it. It is great question whether human society does not change some of the negative feedbacks into positive ones and vice versa. It seems to us, the Lovelock skepticism in The Revenge of Gaia, (2006) in terms that there is only time for retreat, not development, is based just on this clear fact of self-regulation of biosphere and the unclear role of the man in this mechanism.

What remains is SOStainability - application of the SD idea in the complex of natural and human environment. What remains is SOStainability in terms of how long we can discuss what to develop - people, economy and society and what to sustain - nature, life supporting ecosystems and culture (communities)? Can something not(shortage of time for implementation of SD principles on global level) invert this basic common accord? Invert common accord of what to sustain and what to develop in terms of changing positions of humanities and nature in SD concept, i.e. nature and all supporting systems will-object to develop and people will object to sustain? This is not an anagram; this should be the reality of how to survive if the time for sustainability is over. How long will we have time to discuss why to sustain this area with protected species, these landscapes, these life supporting natural systems in every case. From our point of view, the lesson form the history of SD shows the lack of time. We have had time since the prehistoric era to formulate our needs where and what to sustain in terms of natural protection. Since the 18th century we have had time to formulate who and how to sustain nature and how to develop society using appropriate economical tools. Since the 1970 there has been a great discussion and a lot of new arguments on why to sustain natural growing to the knowledge of one unit of biosphere and man. When to sustain is no more declaration from "up to now forever", this moral appeal appears suddenly on the global level taking global climate changes and growing population problems into account. History of SD shows shortening time for its application on the global level and multiply - quicken time of global consequences. We named this crossroad SOStainability. 


\section{ACKNOWLEDGMENT}

The study is a part of the scientific intention No. MSM 0021620841and MSM No. 6007665806. We can realize the study thanks to the grant COST OC 128 A35 and GILDED SSH7-CT-2008-225383

\section{REFERENCES}

Act of Congress (1972). US Marine Mammal Protection Act. Retrieved 6. September 2008, from http://www.nmfs.noaa.gov/pr/pdfs/laws/mmpa.pdf.

Beckerman, W. (1994). 'Sustainable Development': Is it a Useful Concept?' Environmental Values, 3 (3): 191-209.

Beckermann, W. (1995). How Would you Like your 'Sustainability', Sir? Weak or Strong? A Reply to my Critics. Environmental Values, 4 (2):169-179.

Bell, D. (1973). The Coming of the Post-Industrial Society. A Venture in Social Forecasting. NY: Basic Books, New York.

Board on Sustainable Development, National Research Council (1999). Our Common Journey: A Transition toward Sustainability. Washington DC. National Academy Press.

Brundtland Commission - World Commission on Environment and Development (WCED) (1987). Our Common Future. Oxford University Press, Oxford, UK.

Carson, R. (1962). Silent Spring. Houghton Mifflin, Boston, USA.

Coase, R. H. (1960). The Problem of Social Cost. Journal of Law and Economics, 2 (3): 144.

Daly, E. H. (1996). Beyond Growth. Beacon Press, Boston, USA.

Daly, H., Cobb J. B. Jr. (1989). For the Common Good: Redirecting the Economy toward Community, the Environment, and a Sustainable Future. Beacon Press, Boston, Claremont, CA, USA.

Daly, H., Jacobs, M. \& Skolimowski, H. (1995). Discussion. Environmental Values 4 (1): 49-70.

Drucker, P. F. (1995). Managing in a Time of Great Change. Truman Talley Books, New York, USA.

Figge, F. (2005). Capital Substitutability and Weak Sustainability Revisited: The Conditions for Capital Substitution in the Presence of Risk. Environmental Values, 14 (2): 185-201.

Gottlieb, R. S. (1996). This Sacred Earth: Religion, Nature, Environment. Routledge, New York, USA.

Hartwick, J. M. (1990). Natural Resources, National Accounting and Economic Depreciation. Journal of Public Economics, 43 (3): 291-304.

Kates, R. W., Parris, T. M. \& Leiserowitz, A. A. (2005). 'What Is Sustainable Development? Goals, Indicators, Values, and Practice'. Environment: Science and Policy for Sustainable Development, 47 (3): 8-21.

Knight, R. L., S. Riedel. (2002). Aldo Leopold and the Ecological Conscience. Oxford University Press, UK. 
Leńkowa, A. (1978). Ochrona i ksztaltowanie šrodowiska przyrodniczego. (Nature and Environmental protection) In: Michajlow, W., Zabierowski, K., (Eds.) Panswowe wydawnictwo naukowe. 137-186 pp. Warszawa - Krakow, Poland, Tom 1.

Leiserowitz, A. A., Fernandez, L. O. (2008, September/October). 'Toward a New Consciousness: Values to Sustain Human and Natural Communities'. Retrieved 21 September 2008, from http://environment.yale.edu/documents/downloads/o-u/Toward-ANew-Consciousness.pdf.

Leopold, A. (1949). A Sand County Almanac. Oxford University Press, USA.

Marshall, A. (1920). Principles of Economics. $8^{\text {th }}$ edition. Macmillan and Co. Ltd., London. (First published: 1890). Retrieved 16 July 2008, from: http://www.econlib.org/library/ Marshall/marP.html.

Marshall, J., Toffel, M. (2005). Framing the elusive concept of sustainability: a sustainability hierarchy. Environmental Science and Technology 39(3): 673-82.

Maslow, A. (1971). The farther reaches of human nature. New York: The Viking Press.

Meadows, D. H., Meadows, D. L., Randers, J. \& Behrens, W.W. (1972). The Limits to Growth. PAN Books Ltd., London, UK.

Mebratu, D. (1998). Sustainability and sustainable development. Historical and conceptual review. Environmental Impact Assessment Review, 18 (6): 493-520.

Neuymayer, E. (1999). Weak versus Strong Sustainability - Exploring the Limits of Two Opposing Paradigms. Edward Eglar, Cheltenham, UK / Northampton, MA, USA.

Özkaynak, B., Devine, P. \& Rigby, D. (2004). Operationalising Strong Sustainability: Definitions, Methodologies and Outcomes. Environmental Values, 13 (3): 279-303.

Parsons, T. (1966). Societies: Evolutionary and Comparative Perspectives. Prentice Hall Press, Englewood Cliffs, NJ.

Pearce, D. W., Turner, R. K. (1990). Economics of Natural Resources and the Environment. Harvester Wheatsheaf, New York, USA.

Pearce, D., Markandya, A., \& Barbier, E. B. (1998). Blue Print for a Green Economy. Earthscan Publications, London, UK.

Proudhon, P. J. (1840). What is Property? Principle of Right and of Government. Electronic Text Center, University of Virginia Library, USA. Retrieved 24 July 2008, from http:// etext.lib.virginia.edu/toc/modeng/public/ProProp.html.

Redclift, M. (1993). 'Sustainable Development: Needs, Values, Rights'. Environmental Values, 1993 (2): 3-20.

Sen, A. (1984). Resources, Values and Development. Basil Blackwell, Oxford.

Schumacher, E. F. (1989). Small Is Beautiful. Harper Perennial, London, UK.

Smith, A. (1776). An Inquiry Into the Nature and Causes of the Wealth of Nations. (In four volumes), F.R.S. of London and Edinburgh, UK. Retrieved 28 July 2008, from http://www. adamsmith.org/smith/won-b2-c5.htm

Solow, R. M. (1993). An Almost Practical Step Toward Sustainability. Resource Policy, 19 (3): 162-72.

Anonymus (2002, September). The Johannesburg Declaration on Sustainable Development. Retrieved 18 September 2008, from http://www.housing.gov.za/content/ legislation_policies /johannesburg.htm

Toffler, A. (1990). The Third Wave. New York, NY: Bantam Books. 